\title{
ASSISTÊNCIA DE ENFERMAGEM AO CLIENTE QUEIMADO NO AMBULATÓRIO E/OU NO DOMICÍLIO APÓS ALTA DA UNIDADE DE INTERNAÇÃO*
}

\author{
Dulce de Oliveira Azevedo** \\ Elza Maria de Sá Ferreira*** \\ Maria de Fátima de Faria Jóia*** \\ Miriam Gonçalves Matheus***
}

\begin{abstract}
RESUMO - A investigação realizada por quatro enfermeiras objetiva ressaltar a importância desse profissional na assistência ao queimado, após alta hospitalar, para averiguar o aparecimento de possiveis seqüelas e, diagnosticando-as, utilizar meios para miniminzá-las. Também foi preocupação do grupo certificar se as orientações dadas a cliente/famnia sobre higiene, uso de suportes ortopédicos e máscaras haviam sido assimiladas. Os resultados confirmam a ocorrência de problemas relacionados à cicatrização das lesões.
\end{abstract}

ABSTRACT - The investigation conducted by four nurses, emphasizes the importance of this professional on the assistance to burned people, after hospital discharge, in detecting the appearance of possible sequelae, diagnosing them and taking measures to minimize them. Another concern of the group was to verify if the recommendations, about hygiene and use of orthopedic suspenders and masks, given to the patient and his family were understood. The results obtained have confirmed the occurrence of problems in regard to the healing of the lesions.

\section{INTRODUÇÃO}

A falta de preparo da população brasileira a fim de prevenir acidentes por queimadura, assim como o despreparo do Enfermeiro para orientar o Pessoal de Enfermagem como realizar os procedimentos de forma adequada no tratamento do queimado, constituem uma constante nos hospitais brasileiros. O fato é lamentável, visto que as queimaduras ocupam o segundo lugar no mundo e só perdem para as fraturas.

Além do mais, no Brasil, os Serviços de Saúde nada fazem por esses clientes após a alta hospitalar. Por falta de acompanhamento e orientação ocorre o aparecimento de cicatrizes hipertróficas, retraçōes cicatriciais, atrofias, anquiloses e outras deformidades.

Face ao problema, o enfermeiro não deve se esquecer de que tem um papel educativo a desempenhar, e, portanto, as Escolas de Enfermagem necessitam preparar os estudantes de Graduação e Pós-Graduação no sentido de que o futuro profissional possa of erecer cuidados de qualidade, calcados no processo de enfermagem para esse tipo de clientela.

Preocupadas com a falta de acompanhamento do cliente após a alta da Unidade de Queimados, quatro enfermeiras decidiram realizar um estudo sobre 0 assunto, isto 6 , acompanhar os clientes durante um período de quinze meses no ambulatório e/ou no domicílio, para observar a evolução do tecido cicatrizado e se as orientações dadas ao cliente/família foram por eles incorporadas.

A pesquisa tipo exploratória favoreceu a obtenção de dados os quais permitiram fazer inferências, de natureza estatística, para se chegar a conclusões e sugestões.

\section{OBJETIVOS}

- Acompanhar a evolução do cliente queimado no ambulatório e/ou no domicílio, após a alta da Unidade de Internação.

- Investigar a incidência de seqüelas físicas decorrentes da queimadura.

- Verificar como foram assimiladas pelo cliente/família as orientações recebidas durante o tempo de hospitalização.

- Elaborar um roteiro de orientação ao cliente/família, a nível domiciliar, para o auto-cuidado e em especial quanto ao uso adequado de suportes ortopédicos e malhas elásticas.

\section{HIPÓTESES}

- A queimadura constitui, para o cliente, um fator de risco quanto à formação de seqüelas nos três primeiros anos, após o acidente.

- A observância das orientações recebidas sobre o auto-cuidado, durante a hospitalização, favorece a recuperação do cliente queimado, após a alta hospitalar.

\section{SUPORTE TEÓRICO}

No decorrer da vida humana o homem está sempre exposto a uma variedade de agressões e dentre elas destacam-se as que provocam lesões na pele como as queimaduras. Contudo, ele consegue recompor-se graças a processos fisiológicos que o organismo utiliza. Assim, para a restauração da pele lesada, várias reações acontecem em três fases distintas com características peculiares. Fase inicial ou inflamatória, fase da fibroplasia e fase da maturação. Na primeira etapa há uma seqüência de processos como a vaso dilatação, seguida de diminuição do fluxo sanguíneo. Os leucócitos migram e formam uma corrente plasmática levando consigo os eritrócitos para fora do vaso e em

\footnotetext{
* Trabalho classificado em $1^{\circ}$ lugar-Prêmio LAÍS NETO DOS REIS - 40 CBEn-Belém

** Professor Doutor da Escola de Enfermagem ANNA NERYIUFRJ.

*** Enfermeiras do Centro de Tratamento de Queimados do Hospital do Andaraí-INAMPS.
} 
conseqüência há formação do exsudato. Chama-se inflamatória pela característica da lesão. A fase seguinte é a da fibroplasia. É o período em que os fibroblastos começam a se multiplicar e produzem certas substâncias que vão preencher os espaços vazios deixados pela lesão. Aparece então um substrato tecidual o qual é denominado de tecido de granulação e é a partir dele que o processo de regeneração se concretiza. Esta é a terceira fase, isto é, a da maturação. Sobre o tecido de granulação migram células epiteliais que reconstituirão a ferida exposta formando uma nova cobertura (RUSSO, 1976). O autor lembra que a cicatriz é um processo universal que aterroriza o cliente quando a lesão atinge estruturas mais difíceis e, para o fechamento dessa é necessário que entre em ação um mecanismo acessório chamado CONTRAÇÃO. Isso acontece devido às alterações estruturais e bioquímicas no tecido de granualação com o objetivo de diminuir a extensão da área cruenta e facilitar a reconstituição do revestimento epitelial. Após o $3^{\circ}$ mês até o $3^{\circ}$ ano do acidente, ocorre a maturação das cicatrizes hipertróficas que se desenvolvem de modo diferente das cicatrizes simples e lineares. Embora a cicatrização se ja um processo fisiológico cuja função é reparar o tecido agredido, há fatores que interferem de modo prejudicial na cicatrização. São eles de ordem vascular, sistêmica (estado carenciais de doenças) e mecânica.

LARSON (1980) refere que cicatrizes hipertróficas aparecem em ferimentos que atingem áreas profundas, porque há perda de tecido formado de células estáveis e/ou permanentes provocando uma desorganização celular e a ferida é cicatrizada a custa de tecidos fibrosos, com grande probabilidade de quelóides, retrações e contraturas. Elas podem por em risco as funções músculo-esqueléticas do indivíduo, visto que havendo força oposta, a cicatrização tende a encurtar e a força desenvolvida pelos miofibroblastos chegam até deslocar articulações.

Portanto é imprescindível o acompanhamento de clientes com queimaduras de prof undidade total. Isso porque além da desorganização celular, os queimados são propensos à inf ecção local durante o período de hospitalização. Em conseqüência há maior aprofundamento das lesões e posteriormente na fase de maturação da cicatriz, surgem seqüelas (AGUIAR, 1981; AZEVEDO, 1987; BRUNNER \& SUDDARTH, 1985; MELLO, 1972; MODOLIN \& BEVILACQUA, 1985).

Muitas vezes esses clientes tem necessidade de correção cirúrgica com ressecção das cicatrizes e contraturas, bem como incisões relaxadoras e aplicação de enxertos (ARTZ et alii, 1980; CORREIA, et alii, 1980). Os autores afirmam que os enxertos são valiosos nas áreas lesadas quando não há elementos epitelizantes em extensão superior a $8 \mathrm{~cm}$ e quando localizadas em regiões que podem trazer complicações de ordem funcional ou estética.

LARSON (1980) ressalta que as seqüelas podem ser corrigidas sem a cirurgia, contudo explica que é mais trabalhoso e é demorado, porque a cicatrização hipertrófica, anquiloses e outras contraturas são formadas por uma massa de tecido endurecido e coberto por uma camada muito fina de epitelio sem nenhuma resistência. Por isso recomenda a intervenção cirúrgica, mas contra-indica no período ativo de cicatrização, porque a área está altamente vascularizada, causando muito sangramento e portanto prejuízo ao cliente que se encontra debilitado. Contudo lembra que há casos onde as alterações funcionais são de tamanha ordem que exigem ação imediata do especialista, mesmo antes do período de maturação da cicatriz.

RUSSO (1974), CORREIA et alii (1980) e ARTZ et alii (1980) lembram que o cliente para ser submetido a enxertia, deve estar em condições gerais e locais adequadas, pois do contrário o enxerto não será satisfatório. Os autores descrevem enxerto cutâneo como sendo uma parte de tecido que afastado por completo de sua posição original é transferido para outra posição, a fim de corrigir defeitos à distância. Classificam os enxertos quanto à origem, espessura e tamanho. Em relação à origem, dividem os enxertos em auto, alo e heteroenxerto. Autoenxerto quando retirado de uma parte íntegra do corpo do cliente e aplicado no local onde for mais necessário. Aloenxerto quando a pele é de outra pessoa e aplicado no cliente. As fontes mais comuns desses enxertos são os retalhos cirúrgicos, membros amputados e cadáveres. Heteroenxerto ou xenoenxerto é a pele de animais como carneiro, porco, boi, cão e a membrança amniótica, aplicados temporariamente em quem necessita. Quanto à espessura, são divididos em enxertos de espessura parcial e total. Os primeiros tem de 0,02 a $0,08 \mathrm{~cm}$ de pele e os segundos possuem espessura superior. Os mais utilizados são os enxertos finos. Esses of erecem boa "pega" e melhor resultado estético. Conseqüentemente, no de espessura total a cicatrização é mais demorada, o aspecto do local enxertado não é agradável e a área doadora leva mais tempo para reepitelizar.

OLLSTEIN (1980) diz que o enxerto em malha deve ser empregado quando a queimadura é maciça e há pouca pele para cobrir a área lesada. Porém o aspecto final não é bom e por isso não deve ser usado em regiões cosméticas e nem em articulações, porque é muito frágil. Lembra que os enxertos embora nem sempre deixem um aspecto estético final desejável, eles são importantes em especial porque aceleram a cicatrização.

Em relação ao tamanho, RUSSO (1979), CORREIA et alii (1980), ARTZ et alii (1980), referem que há enxertos em grandes lâ minas e em pequenas lâminas. Aquelas cobrem áreas maiores e of erecem um bom aspecto, garantindo a cura em pouco tempo e esses chamados enxertos em "selo" of erecem uma cobertura mais precária, devido a retração inter-insular. Essa técnica é usada quando a quantidade de pele é insuficiente para recobrir toda a área cruenta. Os autores ressaltam ainda a importância de que a coloração da pele retirada da área doadora seja semelhante tanto quanto possível a da área receptora, bem como a textura e a distribuição de pêlos. Os enxertos quando aplicados, podem ser suturados ou não. Há necessidade de imobilizar o cliente nos primeiros dias após enxertia, a fim de que o enxerto não deslize da área onde foi colocado para outra. $\mathrm{O}$ curativo da área doadora é removido, em geral, após uma semana, quando não há infecção e da área receptora, entre 48 a 72 horas da cirurgia, quando o curativo for fechado.

OLLSTEIN (1980) explica que as áreas receptoras para serem enxertadas devem estar vascularizadas, com tecido de granulação vermelho vivo, sem sinal aparente de inf ecção, estar plana e ter epitelização nas bordas da lesão. Afirma que as perdas de enxerto 
ocorrem devido a quatro fatores: momento não apropriado para a enxertia, presença de hematoma local, deslocamento do enxerto da área receptora e sinal de infecção na área enxertada.

E imprescindível que a enfermagem esteja atenta para assegurar a imobilização da área receptora e para prevenir infecção. Sempre que houver exposição de nervos, tendões ou ossos, as áreas devem ser protegidas com enxerto tipo retalho.

Além das cirurgias usadas no tratamento para prevenção de seqüelas em queimados, há os métodos não cirúrgicos que embora mais lentos são de grande valor. Entre outros, destacam-se a mobilização de áreas responsáveis pelo tônus e resistência muscular (ARTZ et alii, 1980; CORREIA et alii, 1980; SIL VEIRA, 1976).

A equipe de enfermagem desempenha um papel muito importante nessa atividade e, portanto, movimentos ativos devem ser estimulados diariamente e os passivos executados desde o início do tratamento. Também a orientação aos clientes no sentido de tomar posições antideformantes devem ser aconselhadas, já que a posição de contratura é a preferida pelo queimado.

Os movimentos são meios pelo quais nos expressamos. A atividade motora é muito importante visto que é um início primário de descarregar emoções. A mobilidade é a capacidade de mover-se livremente, enquanto que a locomoção é o movimento propriamente dito. A imobilização física é uma limitação dos movimentos e o indivíduo quando privado deles, sof re diminuição da força e da tonicidade muscular bem co mo alterações no aparelho locomotor. Toda contratura que se forma ao redor das articulações são difíceis de serem corrigidas, em particular as dos membros inferiores onde se alojam músculos mais resistentes e os tecidos conectíveis são mais pesados. Neste caso a possibilidade de regressão do quadro ao estado normal é bem mais difícil.

Contudo, não se deve esquecer do atendimento às necessidades de locomoção e de mobilidade para prevenir defeitos.

SIL VEIRA (1976) recomenda programas de exercícios para a manutenção dos movimentos de todas as articulações do corpo onde a pele foi lesada exceto no período pós-enxertia, em que a área enxertada deve ficar imobilizada ou quando houve retração articular e neste caso há necessidade de suportes a curto ou a longo prazo para posicionamento do membro lesado. Vale a pena ressaltar que tão logo o paciente volte a ter movimentos completos, os meios auxiliares devem ser dispensados.

A estrutura do corpo é o esqueleto e os ossos se mantêm juntos por ligamentos. Esses pontos de apro ximação são as articulações e é através dos músculos e das articulações que a mobilidade corporal é possível. Autores aconselham dois tipos de exercícios para melhorar a mobilidade. São os de mobilidade articular e os de condicionamento muscular (SIL VEIRA, 1976).

Urge portanto, que a equipe de saúde que está presente diariamente com o cliente, identifique o problema o mais breve possível e determine métodos para que a estrutura óssea não venha exercer pressão sobre a pele e outros tecidos já lesados, limitando a área de nutrição, em especial onde os vasos são superficiais.

Por outro lado há situações que, em vez do cliente ser estimulado à movimentação, ele deve ficar com áreas do corpo imobi łzadas, porque a prevenção, a cura ou a melhoria das limitações resultantes de lesões intra e extrarticulares dependem da imobilização. Esta se dá pelo deslizamento de superfícies articulares e elementos particulares evitando as aderências (UL LOA, 1976).

As medidas mais usadas consistem no posicionamento apropriado do cliente no leito; uso de trações esqueléticas; talas e de malhas compressivas. Essas últimas são empregadas após a formação das cicatrizes que tendem a produzir quelóides. Devem ser usadas numa pressão de mais de $25 \mathrm{mmHg}$ continuamente nas 24 horas. A pressão diminue a vascularização, deprime a tensão parcial do oxigênio tecidual, diminue a quantidade de mucopolissarídios, minimiza a resposta celular, evita a deposição do colágeno, reduz significativamente o linfedema localizado e conseqüentemente diminui a formação de quelóides. Há o capacete de Jobst ou máscara de espuma muito usada em queimaduras de face, porque além de prevenir cicatrizes hipertróficas na área afetada, evita novos ferimentos (LARSON, 1980). Além deles há os colares e calhas empregados para imobilizar áreas articulares comprometidas e as mais sensíveis. Entre os autores destaca-se um grupo que escreveu artigo sobre prevenção e tratamento das contraturas cicatriciais no livro Queimaduras de ARTZ et alii (1980) onde orientam cuidados para cada parte do corpo humano comprometido, cujo objetivo é prevenir a formação de contraturas e cicatrizes hipertróficas. Assim o cliente ainda no período de hospitalização, se está com a cabeça e/ou o pescoço queimados, mantê-lo em posição de "Fou ler" para prevenir edema. O curativo recomendado é o aberto e monta-se uma "rodilha" de espuma envolvida em material absorvente que auxilia no posicionamento da cabeça, deixando as orelhas af astadas do colchão. $\mathrm{O}$ pescoço deve permanecer em extensão moderada, em especial se a lesão atingiu a região anterior ou se é circunferencial. Manter um coxim ou toalha enrolada na porção cervical posterior do pescoço. Quando a articulação gleno-umeral foi atingida, deixar o braço em abdução e num âmgulo de 90 graus e o ombro em flexão de 10 graus. Em relação às articulações dos cotovelos e joelhos, devem ser mantidos em extensão completa com o auxílio de talas. A queimadura que afeta a mão pode significar um sério problema a partir do momento em que as funções das estruturas adjacentes podem ser afetadas, levando a deformação dos dedos. Após curativo, ter o cuidado de separar com gase cada dedo, manter a articulação metacarpofalangiana flexionada, enquanto que as articulações interfalangianas proximais e distais mais o punho, deixá-los estendidos. Esse deve ser protegido com coxim e a seguir prendê-lo com atadura de crepon, fixando-o num suporte de soro. O objetivo é prevenir edema do membro superior e forçar posição correta. $O$ polegar deve ficar fletido em abdução. Os tornozelos e os pés precisam ser conservados em posição ortostática ou neutra e vale insistir na importância do uso das talas para essas áreas. Inclusive, urge empregar meios para prevenir queda plantar.

As lesões nas axilas podem causar contraturas com alterações anatômicas, funcionais e estéticas importantes. Quando elas se estendem pelo torax, causam modificações na postura, assim como no desenvolvi- 
mento do cliente. Por isso manter as axilas afastadas do tronco. Quando os quadris estão comprometidos, conservá-los em posição de abdução de mais ou menos 15 graus. A finalidade é prevenir maceração da queimadura na face interna das coxas (ARTZ et alii, 1980; JUSTIS, 1982).

L ARSON (1980) recomenda o uso de corticóides nos bordos das lesões por queimadura, para prevenir cicatrizes queloidianas. Define-se quelóides como sendo tumores benígnos de consistência dura devido ao crescimento exagerado do tecido cicatricial. Em geral surgem nas áreas onde a pele cicatrizada está sob tensão. Suas formas são diversas: nodular, circular, linear, irregular. Podem ser indolores ou doloridos e por vezes são pruriginosos, além de causar distúrbios funcionais, estéticos e recidivar com relativa freqüência após extirpados. $\mathrm{O}$ tratamento dos quelóides é feito com a aplicação de medicamentos intralesionais ou radioterapia após extirpação por cirurgia. Nos quelóides'extensos e rebeldes, que desfiguram o cliente, o método empregado é o uso das malhas elásticas confeccionadas especialmente para o cliente e empregadas permanentemente durante certo tempo.

\section{METODOLOGIA}

A pesquisa se configura como um estudo descritivo, com observação direta, envolvendo clientes queimados hospitalizados em um Centro de Tratamento de Queimados que comporta vinte e três leitos, de hospital autárquico, na cidade do Rio de Janeiro. O estudo realizado de maio de 1987 a agosto de 1988 se restringiu ao acompanhamento de uma amostra de vinte (20) clientes escolhidos conforme requisitos previamente estabelecidos, isto é, entre os que obtiveram alta da Unidade e concordaram em participar da pes- quisa, permitindo inclusive de serem fotografados nos diferentes estágios de evolução do tratamento. Além do mais se estabeleceu que os escolhidos seriam aque . les que, de qualquer raça ou sexo, apresentassem idade de $\mathrm{O}$ (zero) a 70 anos, cuja queimadura fosse provocada por agentes físicos ou químicos, com lesões de $1^{\circ}$, $2^{\circ}$ e $3^{\circ}$ graus, com extensão de $10 \%$ a $70 \%$ de superfície corporal queimada e estar sujeito a alterações no enxerto, bem como formação de cicatrizes hipertróficas, retrações e outras deformidades.

Para avaliar a amostra foram elaborados-dois instrumentos. $\mathrm{O}$ anexo número 1 consta de uma Ficha de Identificação, contendo dados pessoais, dados relativos à queimadura e dados quanto ao tratamento recebido durante o período de hospitalização no Centro de Tratamento de Queimados. $\mathrm{O}$ anexo número 2 consiste num roteiro de observação sistematizada do cliente no ambulatório e/ou no domicílio e contém quesitos destinados ao levantamento de dados relativos às alterações observadas na pele, no enxerto, nos músculos, nas articulações, nos ossos e outras reações provenientes da queimadura.

Os clientes foram acompanhados por 4 enfermeiras, inicialmente no ambulatório e, posteriormente, no domicílio. A finalidade dessas visitas era verificar se as orientações recebidas pelo cliente/família haviam sido incorporadas, acompanhar a evolução do cliente quanto à cicatrização das lesões; reforçar a necessidade de seguir o tratamento para prevenir retrações e outras seqüelas; encaminhá-lo, se necessário, a serviços especializados e encorajar cliente/família para o auto-cuidado. $\mathrm{O}$ uso correto das calhas e das malhas eram reiteradas a cada visita, e ao terminar se registravam todos os aspectos das lesões e outras anormalidades. As visitas foram feitas, inicialmente, de 15 em 15 dias e posteriormente, a cada mês. $\mathrm{O}$ mínimo de visitas realizadas, por cliente, foram duas e o máximo, seis.

\section{RESUltados}

Tabela 1

\section{DISTRIBUIÇÃO DO NÚMERO DE CLIENTES, SEGUNDO A CLASSE ECONÔMICA E A COR}

\begin{tabular}{|c|c|c|c|c|c|c|c|c|}
\hline \multirow[b]{2}{*}{ Cor } & \multicolumn{2}{|c|}{$\mathbf{A}$} & \multicolumn{2}{|c|}{ B } & \multicolumn{2}{|c|}{ C } & \multicolumn{2}{|c|}{ TOTAL } \\
\hline & fi & $\%$ & fi & $\%$ & fi & $\%$ & fi & $\%$ \\
\hline $\begin{array}{l}\text { Branca } \\
\text { Negra }\end{array}$ & - & - & $\begin{array}{l}3 \\
3\end{array}$ & $\begin{array}{l}50,0 \\
50,0\end{array}$ & $\begin{array}{l}6 \\
8\end{array}$ & $\begin{array}{l}42,9 \\
57,1\end{array}$ & $\begin{array}{r}9 \\
11\end{array}$ & $\begin{array}{l}45,0 \\
55,0\end{array}$ \\
\hline$\Sigma$ & - & - & 6 & 100,0 & 14 & 100,0 & 20 & 100,0 \\
\hline
\end{tabular}


Tabela 2

DISTRIBUIÇĀO DO NÚMERO DE CLIENTES, SEGUNDO A PROFUNDIDADE E A EXTENSĀO DA QUEIMADURA

\begin{tabular}{|c|c|c|c|c|c|c|c|c|c|c|}
\hline \multirow[b]{3}{*}{ Extensão } & \multicolumn{10}{|c|}{ G R A U S } \\
\hline & \multicolumn{2}{|c|}{$1^{\circ}, 2^{\circ}, 3^{\circ}$} & \multicolumn{2}{|c|}{$2^{\circ}, 3^{\circ}$} & \multicolumn{2}{|c|}{29} & \multicolumn{2}{|c|}{ 3 } & \multicolumn{2}{|c|}{ TOTAL } \\
\hline & fi & $\%$ & fi & $\%$ & fi & $\%$ & fi & $\%$ & fi & $\%$ \\
\hline $\begin{array}{r}0-10 \\
10-20 \\
20-30 \\
30-40 \\
40-50 \\
50-60 \\
60-70\end{array}$ & $\begin{array}{l}- \\
2 \\
5 \\
- \\
- \\
\overline{1}\end{array}$ & $\begin{array}{l}\overline{25,0} \\
62,5 \\
- \\
- \\
\overline{12,5}\end{array}$ & $\begin{array}{l}1 \\
1 \\
5 \\
1 \\
- \\
- \\
-\end{array}$ & $\begin{array}{c}12,5 \\
12,5 \\
62,5 \\
12,5 \\
- \\
- \\
-\end{array}$ & $\begin{array}{l}- \\
3 \\
1 \\
- \\
- \\
- \\
-\end{array}$ & $\begin{array}{l}- \\
75,0 \\
25,0 \\
- \\
- \\
- \\
-\end{array}$ & $\begin{array}{l}- \\
- \\
- \\
- \\
\overline{-} \\
-\end{array}$ & $\begin{array}{l}- \\
- \\
- \\
- \\
- \\
-\end{array}$ & $\begin{array}{r}1 \\
6 \\
11 \\
1 \\
- \\
- \\
1\end{array}$ & $\begin{array}{c}5,0 \\
30,0 \\
55,0 \\
5,0 \\
- \\
- \\
5,0\end{array}$ \\
\hline$\Sigma$ & 8 & 100,0 & 8 & 100,0 & 4 & 100,0 & - & - & 20 & 100,0 \\
\hline
\end{tabular}

Tabela 3

DISTRIBUIÇÃO DOS CLIENTES, SEGUNDO AGENTE CAUSAL E TEMPO DE PERMANÊNCIA NA UNIDADE DE INTERNAÇĀO

\begin{tabular}{|c|c|c|c|c|c|c|c|c|}
\hline \multirow[b]{2}{*}{$\begin{array}{l}\text { Tempo de } \\
\text { permanência }\end{array}$} & \multicolumn{2}{|c|}{$\begin{array}{l}\text { Líquidos } \\
\text { Ferventes }\end{array}$} & \multicolumn{2}{|c|}{$\begin{array}{l}\text { Substâncias } \\
\text { Inflamáveis }\end{array}$} & \multicolumn{2}{|c|}{$\begin{array}{c}\text { Contato direto } \\
\text { com a chama }\end{array}$} & \multicolumn{2}{|c|}{ TOTAL } \\
\hline & fi & $\%$ & fi & $\%$ & fi & $\%$ & fi & $\%$ \\
\hline $\begin{array}{l}15-30 \\
30-45 \\
45-60 \\
60-75 \\
75-90 \\
90-105\end{array}$ & $\begin{array}{l}2 \\
1 \\
- \\
- \\
- \\
-\end{array}$ & $\begin{array}{l}66,7 \\
33,3 \\
- \\
- \\
- \\
-\end{array}$ & $\begin{array}{l}2 \\
5 \\
3 \\
2 \\
2 \\
1\end{array}$ & $\begin{array}{r}13,3 \\
33,4 \\
20,0 \\
13,3 \\
13,3 \\
6,7\end{array}$ & $\begin{array}{l}\overline{1} \\
\overline{1} \\
- \\
-\end{array}$ & $\begin{array}{l}\overline{50} \\
\overline{50} \\
- \\
-\end{array}$ & $\begin{array}{l}4 \\
7 \\
3 \\
3 \\
2 \\
1\end{array}$ & $\begin{array}{r}20 \\
35 \\
15 \\
15 \\
10 \\
5\end{array}$ \\
\hline$\Sigma$ & 3 & 100,0 & 15 & 100,0 & 2 & 100,0 & 20 & 100,0 \\
\hline
\end{tabular}

\section{DISCUSSÃO DOS RESULTADOS}

A amostra estudada, composta de 20 clientes com $50 \%$ do sexo masculino e $50 \%$ do sexo feminino, na faixa etária de zero a 70 anos, havendo maior concentraç a de sujeitos $(45 \%)$ na idade entre zero a 10 anos. Esses dados vêm confirmar os achados de RUSSO (1976) em que o percentual foi mais elevado e o cientista dizia serem as crianças menores de 10 anos, as maiores vítimas dos traumas térmicos.

A Tabela 1 mostra que, em relação à classe econômica e à cor, os pacientes com maior percentual $(57,1 \%)$ foram os da raça negra e pertenciam ao grupo de indivíduos mais pobres. Isso talvez se deva ao fato de que essas pessoas são as que moram em condições menos favoráveis em relação às demais classes sociais. O fato vem reforçar o que afirma RUSSO (1976) a respeito dos sujeitos favelados que vivem em condi- ções sub-humanas de moradia e, portanto, mais expostos aos acidentes por traumas térmicos.

A Tabela 2 aponta que, quanto à profundidade e a extensão das lesões, os maiores percentuais referem-se às queimaduras de $1 \%, 2^{\circ}$ e $3 \circ$ graus e de $2^{\circ}$ e $3 \circ$ graus com extensão de 20 - $30 \%$ da SCQ, ambos com $62,5 \%$. Esses índices talvez sejam devidos ao agente causador da queimadura, isto é, substâncias inflamáveis (álcool e petróleo).

A Tabela 3 como já fora explicitada na Tabela 2, revela que a combustão por substância inflamável é o maior percentual entre as causas da queimadura, isto é, $75 \%$. Quanto ao tempo de permanência do cliente no Centro de Tratamento de Queimados o percentual mais alto, ficou em torno dos 30 a 45 dias, com $35 \%$. Tais achados talvez sejam explicados pelo tipo de agente causador das lesões, o qual provoca queimaduras graves exigindo mais tempo de hospitalização. 


\section{Figura 1}

\section{DISTRIBUIÇÃO DO NÚMERO DE CLIENTES, SEGUNDO OBSERVAÇÃO DE}

ALTERAÇÕES NAS ÁREAS CICATRIZADAS

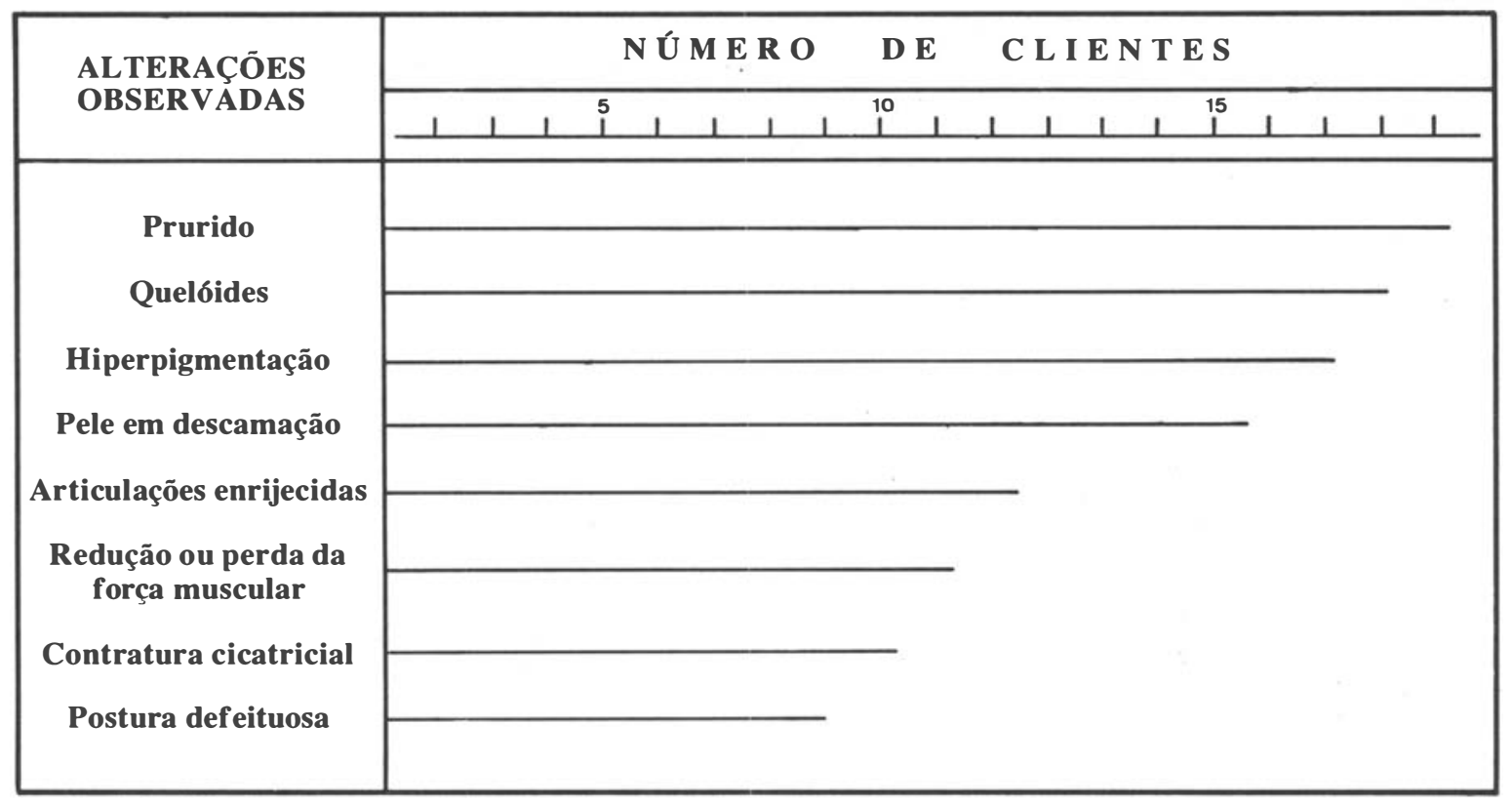

As queimaduras deixam, com certa freqüência, seqüelas cicatriciais, dependendo do local lesado e da extensão comprometida, podendo se tornar mais o menos graves e mais ou menos incapacitantes (5).

A Figura 1 mostra as alterações surgidas nos clientes nas áreas cicatrizadas, após a alta hospitalar. Essas alterações serão discutidas a seguir:

Prurido - Sobressai com os maiores percentuais; isto $\hat{\epsilon}, 100 \%$ dos clientes queixaram-se desse fenômeno reacional. O fato talvez se deva, porque todo trauma térmico cuja temperatura ultrapassa a $65^{\circ} \mathrm{C}$, provoca várias alterações na estrutura cutânea. Além disso, a aparência da pele, em vários pacientes traduziu o grau de vulnerabilidade do tecido reconstituído, isto E, uma pele seca descamando constantemente e com grande intensidade. Supõe-se que seja conseqüência dos freqüentes e prolongados banhos, usando substâncias antissépticas à base de iodo, no período de hospitalização e a não observância, por parte dos clientes no domicílio, quanto ao uso tópico de substâncias neutras, para efeito de lubrificação.

Quelóides - Entre os 20 clientes da amostra 18 (90\%) apresentaram quelóides, sendo que, $14(70 \%)$ foram executados e mesmo assim o apresentaram. Observou-se que essa anomalia nem sempre era apresentada pelo cliente na primeira visita feita pelo grupo pesquisador, mas surgia à medida que os meses iam passando, sendo a raça negra a mais atingida.

$\mathrm{O}$ fato vem comprovar o que a literatura refere sobre o assunto, isto é, os quelóides aparecem no período de maturação da cicatriz, ou seja, do 30 ao 18 o mês após a queimadura. $\mathrm{O}$ processo ocorre devido a aumento da vascularização, dos fibroblastos, dos miofibroblastos, da deposição de colágeno, do material intersticial e do edema (AGUIAR, 1981; ARTZ et alii,
1980; SIL VEIRA, 1976).

Hiperpigmentação - Foi uma reação observada em $85 \%$ dos clientes da amostra. Talvez seja devido ao resultado do excesso de melanina que aparece posteriormente, por vezes generalizada nas áreas restauradas.

Articulações enrijecidas - Isso se deve ao fato do queimado procurar uma posição de alívio, em conseqüência do estado de imobilização ou mobilização militada das articulações, resultando em mais um tipo de deformidade.

Ela esteve presente em $60 \%$ da clientela estudada e fica evidenciado que é um percentual relativamente elevado. Autores referem que essas deformidades são seqüelas comuns, após o período de recuperação do trama técnico, porém podem ser minimizadas por meio de movimentos ativos, passivos e outros métodos utilizados. Esse fenômeno vem aumentando na medida em que os queimados estão conseguindo sobreviver, devido às melhores condições de tratamento durante a hospitalização (AGUIAR, 1981; CORREIA et alii, 1980; OL LSTEIN, 1980).

SIL VEIRA (1976) alerta para que a enfermagem fique atenta ao problema a fim de diagnosticar e intervir assim que perceber a necessidade de mobilidade af etada. Lembra que a função motora no queimado está na dependência do sistema ósseo, cartilaginoso, muscular, ligamentos e aponeuroses. Aconselha que seja instituído para cada cliente um programa terapêutico tanto no período de hospitalização, quanto no domicílio.

Todo esforço deve ser feito para encorajar o indivíduo a realizar movimentos articulares o mais precocemente possível, deambulando, permanecendo fora do leito e exercitando todas as articulaçōes envolvidas. 
Redução ou perda da força muscular - Os dados permitem inferir que 55\% dos clientes apresentou essa deficência. São vários os eventos que conduzem à diminuição da força muscular no queimado e, felizmente, eles podem ser diminuídos, dependendo de um programa de exercícios para recuperação da função motora. Quanto maior for a profundidade das lesões, maior será a probabilidade na limitação da força muscular. Por isso o programa deve incluir avaliação e supervisão do enfermeiro em relação ao cliente de alcançar melhores resultados.

Contraturas Cicatriciais - As contraturas cicatriciais revelam um percentual de 50\% entre os clientes da amostra. Esses achados vêm confirmar o resultado de experiências realizadas por ARTZ et alii (1980) quando ressaltam que tais anormalidades dificilmente são evitadas em queimaduras com lesões que atingẹm estruturas mais profundas. contudo, referem que podem ser diminuídas pelo uso de curativos compressivos, posicionamento adequado do cliente com calhas, colares cervicais e malhas, para manter posição correta das articulações. Esses defeitos também podem ser decorrentes de quelóides não exteriorizados.

Postura Defeituosa - Os valores corrigidos quanto à postura defeituosa, embora sendo bastante graves, foram os que menos concorreram como fatores agravantes em relação à reabilitação dos pacientes, com o percentual de $45 \%$. Os dados permitem questionar sobre o porque da persistência dessa alteração adquirida durante o período de hospitalização. Talvez seja devido ao fato de que, certas posiçōes, embora não sendo as mais adequadas, são as escolhidas pelo cliente numa tentativa de minimizar a dor. Isto pode decorrer também do fato de que os clientes acometidos pelo trauma térmico, pertencem, na maioria das vezes, à classe pobre e não se preocupam com sua auto-imagem.

O percentual inferior às demais alterações observadas, com certeza, se deve às açōes de enfermagem durante o período de hospitalização quando instituia-se um programa terapêutico diário, sendo esse também estimulado no domicílio.

Outros - O acompanhamento do cliente no domicílio revelou um dado significativo quanto às outras alteraçōes físicas e psicológicas observadas. Entre as físicas destacaram-se: hipersensibilidade, dormência, ardência, dor, cefaléia, bridas, alterações psicológicas, queda $\mathrm{p}$ tintar e, entre as psicológicas destacamos; temor ao fogo, mutismo, choro persistente, insônia, solidão, estados depressivos, ansiedade e grande dificuldade de readaptação ao meio social, devido às cicatrizes hipertróficas e outras deformidades.

Todas essas alterações talvez sejam provenientes do desequilíbrio homeostático causado pela queimadura no homem enquanto ser holístico, com suas necessidades biopsicossociais espirituais af etadas.

\section{CONCLUSÕES}

Diante dos questionamentos que surgem quanto às seqüelas físicas adquiridas pelos queimados após alta hospitalar e a falta de assistência de enfermagem a essa clientela, levaram as pesquisadoras a estudar o assunto mais minuciosamente, constatando que praticamente nada se tem feito em benefício desses sujeitos, no domícilio.
Sem dúvida alguma, o desencanto por parte dos enfermeiros em cuidar do queimado, a formação deficiente do estudante de enfermagem em relação à ciência enquanto prática e a falta de compromisso dos docentes em preparar o enfermeiro para as ações preventivas, curativas e de reabilitação, constituem fatores impeditivos para solucionar o problema.

Em relação aos acidentes por queimadura, o enfermeiro deve estar apto a orientar a comunidade para prevenir o acidente, dispensar cuidados a nível hospitalar, onde as exigências são grandes e acompanhá ło durante a fase de reabilitação, isto $\varepsilon$, do $6^{\circ}$ ao $18^{\circ}$ mês de maturação completa da cicatriz, já que é nesse período que as deformações surgem com maior freqüência.

Certamente, essa atividade não é uma questão fácil, pois encontramos durante as visitas no domicílio uma realidade sócio-econômica bastante constrange dora, onde as precárias condiçōes de habitação, de higiene e a falta de segurança no trabalho, contribuem com uma faixa expressiva no cômputo geral dos acidentes por traumas térmicos. Além disso, há crianças e adultos que foram queimados e estão amedrontados, ansiosos, rejeitados, envergonhados devido às cicatrizes e com grande dificuldade de readaptação às atividades anteriores, por causa de impedimento funcional.

Os resultados obtidos nesse estudo deixaram claro que as orientações fornecidas ao cliente no momento da alta hospitalar não foram seguidas adequadamente e algumas abandonnadas pelos clientes, acarretando com isso, conseqüências adversas e com mau prognóstico.

\section{SUGESTÕES}

Em face da evidência do problema, consideramos que:

- Os diretores e coordenadores de Escolas de Enfermagem se conscientizem da importância de incluir nos programas, conhecimentos teóricos e práticos sobre a assistência de enfermagem no tratamento e na reabilitação do queimado.

- Os membros do corpo docente e enfermeiras realizem uma ampla atividade educativa no sentido de orientar o queimado para o auto-cuidado.

- A equipe de enfermagem estimule o cliente, quando hospitalizado, a realizar movimentos ativos e permitir se façam movimentos passivos para prevenir seqüelas.

- Orientar, no domicílio, o auto-cuidado quanto à higiene corporal, o curativo das lesões abertas, uso de suportes ortopédicos e malhas elásticas.

\section{REFERÊNCIAS BIBLIOGRAFICAS}

1 AGUIAR, A. Prevenção de infecções em situação da alto risco. J. Ped., 50:197-202, 1981.

2 ARTZ, C. P.: MONCRIEF, J. A. \& PRUITT, Jr. B. A Queimaduras, 1. ed., Rio de Janeiro, Interamericana, 1980.

3 AZEVEDO, D. O. Contribuiçâo ao estudo da prevalência de infecção por Pseudomonas aeroginosa em pacientes queimados, hospitalizados. Ribeirão Preto, USP, Escola de Enfermagem, 1987, (tese de dout. - USP). 
4 BRUNNER, L. S. \& SUDDARTH, D.S. Tratado de Enfermagem Médico-Cirúrgica, 5. ed., Rio de Janeiro, Interamericana 1985.

5 CORREIA, P. C.; BRANCO, P. D.; AMARY, A. Quemaduras, Fisiopatologia, diagnóstico, avaliaçāo e seu tratamento clínico e cirúrgico. São Paulo, Livraria Atheneu 1980.

6 COUTINHO A. C. et al Dicionário enciclopédico de medicina, 3. ed., Rio de Janeiro, Livraria Luso Espanhola e Brasileira.

7 JUSTIS, E. Travomatiomo da mäo. In: SCHWARTZ et alü. Emergências Médicas. Rio de Janeiro, Interamericana, 1982. vol. 2.

8 LARSON, D. Prevenção de tratamento das contraturas cicatriciais. In: Artz, C. P.; Moncrief, J. A. \& Pruitt, Jr. B. A. Queimaduras. Rio de Janeiro, Interamericana 1980.
9 MELLO, C. G. A coordenação das medidas preventivas contra as infecçōes hospitalares. Revista Paulista de Hospitais, 20:18-24, 1972.

10 MODOLIN, M. \& BEVILACQUA, R. G. Cicatrização das feridas. Síntese das aquisiçōes recentes. Revista Brasileira Clínica Terapêutica, 14:56-64, 1985.

11 OLLSTEIN, R. N. Queimaduras. In: JUNIOR, T. F. N. - Técnica Cirúrgica Básica, 3. ed., Rio de Janeiro, Interamericana 1980.

12 RUSSO, A. C. - Tratamento das queimaduras. 2. ed., São Paulo, Savier, 1976.

13 SILVEIRA, G. X. Aspectos assistênciais de enfermagem nas necessidades de locomoção e mobilidade. Enfermagem Novas Dimensões 2: 258-264, 1976.

14 ULLOA, M. G. Queimaduras huonanas. México, Interamericana 1960. 